J. Lake Sci. (湖泊科学) , $2007, \mathbf{1 9 ( 3 ) ~ : 3 4 0 - 3 4 4 ~}$

http:// www. jlakes. org. E-mail: jlakes@ niglas. ac.cn

(c) 2007 by Journal of Lake Sciences

\title{
湖北浮桥河水库浮游植物初级生产力及其管理
}

\author{
朱爱民 ${ }^{1}$, 刘家寿 ${ }^{* * *}$, 胡传林 ${ }^{1}$, 吴晓辉 ${ }^{* * *}$, 程临英 $^{2}$, 彭建华 ${ }^{1}$, 俞伏虎 $^{1}$, 杨大兴 ${ }^{2}$ \\ $(1$ : 水利部、中国科学院水工程生态研究所,武汉 430079) \\ $(2$ : 湖北省麻城市浮桥河水库管理处, 麻城 431606$)$
}

提 要: 浮桥河水库浮游植物水柱日生产量变幅为 $0.34-4.99 \mathrm{~g} /\left(\mathrm{m}^{2} \cdot \mathrm{d}\right)$, 最低值出现在下游冬季, 最高值出现在中游秋 季, 年平均值 $2.75 \mathrm{~g} /\left(\mathrm{m}^{2} \cdot \mathrm{d}\right)$. 季节变化: 秋季 > 夏季 > 春季 > 冬季, 与浮游植物叶绿素 a 含量和生物量的季节变化一 致;水平分布: 中游略高于上游, 下游最低, 与浮游植物叶绿素 $\mathrm{a}$ 含量的水平分布完全一致. 表层日生产量占水柱日生产量 $53.81 \%$. 与 1980 年同期相比, 浮游植物初级生产力增加了 1.2 倍. 分析表明, 磷含量增加是浮游植物初级生产力提高的 关键因子. 应用能量收支法估算浮桥河水库鲢鳙渔产潜力为 $772 \mathrm{t}, 516.0 \mathrm{~kg} / \mathrm{hm}^{2}$. 从渔业管理和水质管理角度讨论了合 理利用浮游植物初级生产力的措施.

关键词: 浮桥河水库; 浮游植物初级生产力; 渔业管理; 水质管理

\section{Primary production of phytoplankton and its management in Fuqiaohe Reservoir, Hubei Province}

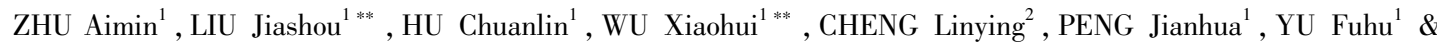
YANG Daxing ${ }^{2}$

(1:Institute of Water-Engineering Ecology, the Ministry of Water Resources P. R. C. and the Chinese Academy of Science, Wuhan 430079 ,P. R. China)

(2:Management Office of Fuqiaohe Reservoir, Macheng city, Hubei Province, Macheng 431606,P. R. China)

\begin{abstract}
The primary production of phytoplankton was investigated from April 1997 to January 1998 in Fuqiaohe Reservoir of Hubei Province. It ranged from $0.34-4.99 \mathrm{~g} /\left(\mathrm{m}^{2} \cdot \mathrm{d}\right)$, with the highest values in the middle reaches by horizontal distribution and in autumn by seasonal distribution, and with the smallest in the lower reaches and in winter. The annual average was $2.75 \mathrm{~g} /\left(\mathrm{m}^{2} \cdot \mathrm{d}\right)$. The primary production of phytoplankton was higher in the middle reaches, followed by the upper, and lower reaches. As a result of phosphorus increase, the primary production of phytoplankton increased 1.2 times comparing with the result of the same period of 1980 . The production potential of silver carp and bighead estimated was $77.2 \times 10^{4} \mathrm{~kg}$, or $516.0 \mathrm{~kg} / \mathrm{ha}$. The techniques of reservoir fishery management and water quality management by making rational use of the primary production of phytoplankton were discussed.
\end{abstract}

Keywords: Fuqiaohe Reservoir; primary production of phytoplankton; fishery management; water quality management

浮桥河水库位于大别山南麓湖北省麻城市境内, 地处东经 $110^{\circ} 52^{\prime}$ 、北纬 $31^{\circ} 10^{\prime}$, 于 1960 年建成, 是一 座具有灌溉、养鱼、发电和防洪等多功能的大型丘陵型水库. 集雨面积 $381 \mathrm{~km}^{2}$, 总库容 $5.41 \times 10^{8} \mathrm{~m}^{3}$, 平均 水深 $5.6 \mathrm{~m}$, 养鱼面积 $1496 \mathrm{hm}^{2}$, 属多年调节水库.

有关水库浮游植物初级生产力的报道过去主要偏重于渔产潜力估算、水体营养类型评价, 以及其影响

* 国家“九五”科技攻关计划专题( $96-008-02-04)$ 、科技部农业科技成果转化项目 (04EFN216800346) 联合资助. $2006-05-25$ 收稿;2006-09-21 收修改稿. 朱爱民,男,1963 年生,副研究员,E-mail:zham9928@ sina. com.

** 现在中国科学院水生生物研究所工作. 
因素的研究 ${ }^{[1-7]}$, 缺乏针对水库初级生产力特点进行渔业和水质管理方面的研究. 浮桥河水库水草极少, 浮游植物是水体的主要初级生产者. 中国科学院水生生物研究所曾于 1980 年对该水库浮游植物初级生产 力进行过初步调查 ${ }^{[8]}$,但有关该水库浮游植物初级生产力的专门研究尚未见报道. 我们分别于 1997 年 4 月至 1998 年 1 月按季度对该水库浮游植物及其初级生产力进行了周年研究、2005 年 5 月和 12 月对浮游植 物和水体理化再次进行了调查, 并对 1980 年以来浮游植物初级生产力的发展进行探讨, 以揭示这座位于长 江中游大型丘陵型水库浮游植物初级生产力的生态学特点, 为水库的渔业管理和水质管理提供参考.

\section{1 工作方法}

浮游植物初级生产力测定与水生生物、水体理化指标的周年调查同步进行,在全库 13 个调查采样点 中 $^{[9]}$, 选择其中的 3 点 (下游)、6 点 (中游) 和 11 站 (上游) 分别于 1997 年 4 月 (春季)、 7 月 (夏季)、10 月 (秋季) 和 1998 年 1 月 (冬季) 测定一次浮游植物初级生产力和浮游植物叶绿素 a. 初级生产力测定采用黑 白瓶测氧法 ${ }^{[10]}$, 黑白瓶悬挂水层共 5 层, 即表层、 $1 / 2$ 倍透明度、 1 倍透明度、 2 倍透明度和 3 倍透明度处, 曝 光时间 $24 \mathrm{~h}$. 浮游植物叶绿素 $\mathrm{a}$ 样品采集水层与浮游植物一致 ${ }^{[9]}$, 取 $250 \mathrm{ml}$ 混和水样. 按有关文献进行处 理和计算 ${ }^{[10]} .2005$ 年浮游植物调查较 1997 年减少 2 个点, 即只保留上游较窄断面 (9、10、11 点) 中的 11 点,其它采样点不变,采样和处理方法等也不变.

\section{2 结果与分析}

\section{1 初级生产力}

2.1 .1 水柱日生产量 浮游植物水柱日生产量变幅为 $0.34-4.99 \mathrm{~g} /\left(\mathrm{m}^{2} \cdot \mathrm{d}\right)$, 年平均值为 $2.75 \mathrm{~g} /\left(\mathrm{m}^{2} \cdot \mathrm{d}\right)$ (表 1). 最低值出现在冬季下游, 这时总氮与总磷比 ( N/P 比) 在各站不同季节中最高 (达 19.8), 总磷含量 在各站不同季节中最低, 比中、上游同期低 $35.8 \%$ 以上 ${ }^{[11]}$, 磷限制最明显. 最高值出现在秋季中游, 与该站 叶绿素 $\mathrm{a}$ 含量在各站中全年最高一致 (表 1). 季节变化为 : 秋季 $>$ 夏季 $>$ 春季 $>$ 冬季, 与浮游植物叶绿素 $\mathrm{a}$ 含量 (表 1) 和生物量 ${ }^{[9]}$ 的季节变化一致, 秋季生产量最高与浮游植物现存量 ${ }^{[9]}$ 、叶绿素 a(表 1) 和总磷含 量 ${ }^{[11]}$ 最高一致, 冬季最低与总磷含量全年最低一致 ${ }^{[11]}$. 表明总磷含量对初级生产力有明显的影响. 水平 分布表现为下游最低,中游略高于上游,与浮游植物叶绿素 a 含量的水平分布完全一致 (表 1 ).

表 1 浮桥河水库浮游植物叶绿素 $\mathrm{a} 、$ 生产量及代谢类型

Tab. 1 Chl. a,primary production of phytoplankton and $P / R$ in Fuqiaohe Reservoir

\begin{tabular}{|c|c|c|c|c|c|c|c|c|c|c|c|}
\hline \multirow{2}{*}{ 时间 } & \multicolumn{4}{|c|}{ 叶绿素 $\mathrm{a}(\mu \mathrm{g} / \mathrm{L})$} & \multicolumn{4}{|c|}{ 表层/水柱日生产量 $\left(\mathrm{g} /\left(\mathrm{m}^{2} \cdot \mathrm{d}\right)\right)$} & \multicolumn{3}{|c|}{$P / R$} \\
\hline & 下游 & 中游 & 上游 & 平均 & 下游 & 中游 & 上游 & 平均 & 下游 & 中游 & 上游 \\
\hline \multirow[t]{2}{*}{ 春季 } & 0.86 & 2.43 & 1.61 & 1.63 & 1.79 & 0.51 & 0.86 & 1.05 & 1.68 & 1.37 & 1.50 \\
\hline & & & & & 2.40 & 1.52 & 1.63 & 1.85 & & & \\
\hline \multirow[t]{2}{*}{ 夏季 } & 6.8 & 4.54 & 42.46 & 17.93 & 1.40 & 1.98 & 3.16 & 2.18 & 1.82 & 1.55 & 1.97 \\
\hline & & & & & 3.85 & 4.19 & 4.54 & 4.19 & & & \\
\hline \multirow[t]{2}{*}{ 秋季 } & 18.1 & 72.22 & 31.85 & 40.72 & 1.85 & 2.38 & 2.73 & 2.32 & 2.49 & 2.26 & 1.55 \\
\hline & & & & & 3.64 & 4.99 & 4.46 & 4.36 & & & \\
\hline \multirow[t]{2}{*}{ 冬季 } & 1.63 & 1.67 & 1.16 & 1.49 & 0.21 & 0.65 & 0.25 & 0.37 & 1.26 & 1.29 & 1.30 \\
\hline & & & & & 0.34 & 0.84 & 0.56 & 0.58 & & & \\
\hline \multirow[t]{2}{*}{ 年平均 } & 6.85 & 20.22 & 19.27 & 15.45 & 1.31 & 1.38 & 1.75 & 1.48 & 1.81 & 1.62 & 1.58 \\
\hline & & & & & 2.56 & 2.89 & 2.80 & 2.75 & & & \\
\hline
\end{tabular}

浮桥河水库是一座长江中游具有代表性的大型丘陵型浅水水库, 其浮游植物水柱日生产量年平均值比 湖北陆水水库和四川黑龙滩水库 (均为大型深水水库) 的低, 主要是浮游植物密度低 ${ }^{[5,6]}$. 大大高于河南宿 鸭湖水库 (大型平原型水库) 年平均值, 主要是宿鸭湖水库水浅 (平均水深 $1.23 \mathrm{~m}$ ), 风浪对底泥扰动使得水 
体透明度很低 (年平均值为 $11 \mathrm{~cm}$ ) 的缘故 ${ }^{[3]}$. 比东湖 ${ }^{[12]} 1979-1986$ 年平均值 $\left(\mathrm{I}\right.$ 站 $6.19 \mathrm{~g} /\left(\mathrm{m}^{2} \cdot \mathrm{d}\right)$, II 站 $4.43 \mathrm{~g} /\left(\mathrm{m}^{2} \cdot \mathrm{d}\right)$ 低很多.

2.1 .2 表层日生产量 浮游植物表层 (一倍透明度水层) 日生产量变幅为 $0.21-3.16 \mathrm{~g} /\left(\mathrm{m}^{2} \cdot \mathrm{d}\right)($ 表 1$)$. 春季表层日生产量占水柱日生产量的平均值为 $53.63 \%$,夏季 $51.07 \%$,秋季 $53.24 \%$,冬季 $61.26 \%$. 表明 浮桥河水库冬季浮游植物生产量主要在表水层, 可能与冬季浮游植物更多分布在表层有关. 上游表层日生 产量占水柱日生产量的平均值为 $62.50 \%$, 中游 $47.75 \%$, 下游 $51.17 \%$. 上游表层生产量较高, 中游偏低, 可能也与浮游植物的水层分布多少有关. 浮游植物表层日生产量占水柱日生产量的年平均值 $(53.81 \%)$ 与 其他一些湖泊的情况类似 ${ }^{[12-14]}$.

2.1 .3 水体代谢类型和营养类型 浮游植物水柱生产量 $(P)$ 与呼吸量 $(R)$ 的比值 $(P / R)$ 是反映水体代谢类 型的重要指标. 浮桥河水库 $P / R$ 平均值为 1.67 , 即生产量大于呼吸量, 为自养型水体. 水平分布为, 上游 $<$ 中游 <下游 (表 1), 表明水体代谢状况自上游至下游逐步变好. 季节变化为,秋季 $>$ 夏季 $>$ 春季 $>$ 冬季 (表 $1)$, 表明水体代谢状况秋季最好, 这主要是秋季浮游植物生产力最高, 而水温较夏季低 ${ }^{[11]}$, 浮游植物呼吸作 用降低, $P / R$ 最高, 冬季初级生产力全年最低, 由于水温最低, 浮游植物处于死亡阶段, $P / R$ 最低.

浮桥河水库 $P / R$ 的季节特点与黑龙滩水库一致,相同季节的 $P / R$ 要高于黑龙滩水库 ${ }^{[6]}$, 表明浮桥河 水库水体的异氧作用较弱,水体自养状况好于黑龙滩水库.

Winberg ${ }^{[15]}$ 根据前苏联湖泊的资料, 提出最高水柱日产量在 $0.3-0.7 \mathrm{~g} /\left(\mathrm{m}^{2} \cdot \mathrm{d}\right)(\mathrm{C})$ 为中营养型湖泊, $0.7-2 \mathrm{~g} /\left(\mathrm{m}^{2} \cdot \mathrm{d}\right)(\mathrm{C})$ 为富营养型湖泊, $2-4 \mathrm{~g} /\left(\mathrm{m}^{2} \cdot \mathrm{d}\right)(\mathrm{C})$ 为高度富营养型湖泊. 何志辉 ${ }^{[16]}$ 综合了国外 学者的研究, 提出浮游植物初级生产量 $<1 \mathrm{~g} /\left(\mathrm{m}^{2} \cdot \mathrm{d}\right)\left(\mathrm{O}_{2}\right)$ 为贫营养型湖泊, $1-3 \mathrm{~g} /\left(\mathrm{m}^{2} \cdot \mathrm{d}\right)$ (1)为中营养型 湖泊, 3-7 g/ $\left(\mathrm{m}^{2} \cdot \mathrm{d}\right)$ 为富营养型湖泊, > $7 \mathrm{~g} /\left(\mathrm{m}^{2} \cdot \mathrm{d}\right)$ 为超富营养型湖泊. 浮桥河水库最高水柱日生产 量为 $4.99 \mathrm{~g} /\left(\mathrm{m}^{2} \cdot \mathrm{d}\right)\left(\mathrm{O}_{2}\right)$ ( 折合 $1.497 \mathrm{~g} /\left(\mathrm{m}^{2} \cdot \mathrm{d}\right)(\mathrm{C})$ ), 水柱日生产量年均值为 $2.75 \mathrm{~g} /\left(\mathrm{m}^{2} \cdot \mathrm{d}\right)\left(\mathrm{O}_{2}\right)$. 按 照上述划分标准, 浮桥河水库均属中富营养型. 综合 Richard-Thompson、Wetzel、美国环保局和 OECD 提出根 据叶绿素 $\mathrm{a}$ 含量划分营养类型的四种标准 ${ }^{[17]}$, 浮桥河水库叶绿素 a 含量平均值为 $15.45 \mu \mathrm{g} / \mathrm{L}$, 属中偏富营 养类型. 这与吴晓辉的报道一致 ${ }^{[9]}$.

\section{2 初级生产力的发展}

与 1980 年 $\left(1.99 \mathrm{~g} /\left(\mathrm{m}^{2} \cdot \mathrm{d}\right)\left(\mathrm{O}_{2}\right)\right.$ 相比 ${ }^{[8]}, 1997$ 年同期浮桥河水库浮游植物水柱日生产量 $\left(4.36 \mathrm{~g} /\left(\mathrm{m}^{2}\right.\right.$ $\cdot \mathrm{d})\left(\mathrm{O}_{2}\right)$, 表 1$)$ 增长了 1.2 倍. 从主要水质指标比较来看 (表 2$)$, 尽管浮游植物密度、氨氮、总氮和透明度 呈不同程度下降(分别下降了 $37.10 \% 、 20.28 \% 、 59.66 \% 、 51.13 \%$ ), 但总磷含量大幅增加 (升高了 1.31 倍), 水体总氮与总磷比 (N/P 比) 由 1980 年的 $30.5 / 1$ 下降到 1997 年同期的 $5.3 / 1$, 使得水体氮磷比 $(\mathrm{N} / \mathrm{P})$ 更接近浮游植物代谢所适宜的氮磷比 $\mathrm{N} / \mathrm{P}(7.2 / 1)^{[18]}$, 表明磷是影响浮桥河水库初级生产力发展的关键因 子. 这与前面的分析一致. 水体营养状况也由 1980 年秋季的中营养型发展到 1997 年秋季的富营养型.

表 2 浮桥河主要水质指标比较

Tab. 2 The comparison of some water quality parameters in Fuqiaohe Reservoir in 1980,1997 and 2005

\begin{tabular}{cccccc}
\hline & 透明度 $(\mathrm{cm})$ & 氨氮 $(\mathrm{mg} / \mathrm{L})$ & 总氮 $(\mathrm{mg} / \mathrm{L})$ & 总磷 $(\mathrm{mg} / \mathrm{L})$ & 浮游植物密度 $\left(\times 10^{4} \mathrm{ind} . / \mathrm{L}\right)$ \\
\hline 1980 年 & 150 & 0.212 & 1.19 & 0.039 & 193.0 \\
1997 年 & 73.3 & 0.169 & 0.48 & 0.090 & 121.4 \\
1997 年春季 & 191.7 & 0.225 & 0.999 & 0.071 & 8.6 \\
2005 年春季 & 156.7 & 0.157 & 0.623 & 0.114 & 60.6 \\
1997 年冬季 & 173.3 & & 0.613 & 0.048 & 9.7 \\
2005 年冬季 & 123.3 & 0.380 & 0.595 & 0.057 & 10.1 \\
\hline
\end{tabular}

(1) 即 $g /\left(m^{2} \cdot d\right)\left(O_{2}\right)$, 以下同. 
与 1997 年相比,2005 年同期水体透明度、氨氮和总氮继续下降, 总磷和浮游植物密度有不同程度升高 (表 2), 水体总氮与总磷比 (N/P 比) 分别由 1997 年春季和冬季的 14.1/1、12.8/1 下降到 2005 年同期的 $5.5 / 1 、 10.4 / 1,2005$ 年水库初级生产力较 1997 年同期会有所提高. 2005 年春季总磷含量超过 1997 年全年 最高值、较年平均值增加了 $67.6 \%{ }^{[11]}$, 在水文条件影响下, 一年中水库总磷含量春季第二低而秋季最 高 $^{[11]}$, 可以推测 2005 年秋季总磷含量更高, 与秋季氮含量降低相比, 可能会使 2005 年秋季总氮与总磷比 (N/P 比) 低于 1997 年秋季 (5.3/1) 水平, 导致氮相对缺乏. 因此, 从 1980 年到 2005 年, 随着水体磷含量的 增加, 水库初级生产力将提高, 同时, 由于总氮含量降低,在 2005 年秋季, 初级生产力可能会受到氮不足的 限制.

\section{3 渔产潜力估算}

浮游植物初级生产是浮桥河水库物质生产的基础,水库所有鱼类产量基本上都来源于浮游植物初级生 产量, 它们之间存在着必然联系. 用能量估算法 ${ }^{[14]}$ 估算浮桥河水库渔产潜力如下.

浮游植物对鲢鳙鱼的供饵能力 $(F s c)$ :

$F s c=$ 水库年产量 $\times P n a / P g a \times$ 鱼类对浮游植物利用率 $\times$ 氧的热当量 式中, $P n a / P g a$ 为 0.8 , 鱼类对浮游植物利用率为 0.5 , 氧的热当量为 14.686 . 通过计算, $F s c$ 为 $88204.57 \times$ $10^{6} \mathrm{KJ}$.

鲢鳙, 渔产潜力 $(F h y, F a r)$ :

Fhy $=F s c \times E h y \times H y / C, F a r=F s c \times E a r \times A r / C$

式中, $C$ 为 $1 \mathrm{~g}$ 鲜鱼肉的热当量 $(5.021 \mathrm{KJ}), E h y$ 和 $E a r$ 分别为鲢鳙对浮游植物的能量转化率, 分别为 0.032 和 0.072. $H y$ 和 $A r$ 分别为鲢鳙相对比例, 若 $H y=0.7, A r=0.3$, 计算得出鲢的渔产潜力 $(F h y)$ 为 $393 \mathrm{t}$, 鳙的 渔产潜力 $(F a r)$ 为 $379 \mathrm{t}$, 合计 $772 \mathrm{t}$, 单产 $516.0 \mathrm{~kg} / \mathrm{hm}^{2}$.

\section{3 讨论}

\section{1 针对浮游植物初级生产力发展的水质管理措施}

浮桥河水库水体营养状况已达中富营养型, 1997 年夏秋季 ${ }^{[9]}$ 和 2005 年冬季中上游部分区域出现蓝藻 “水华”,作为饮水功能日趋重要的大型丘陵型水库,其富营养化的发展应该引起足够的重视. 从浮游植物 初级生产力周年变化来看, 磷是影响浮游植物初级生产力的最重要因子, 其含量的高低影响着浮游植物初 级生产力的高低. 从浮游植物初级生产力发展来看, 磷是提高浮桥河水库浮游植物初级生产力的关键因 子. 由于磷对浮游植物初级生产力的影响且其含量一直持续增加, 因此, 防治浮桥河水库富营养化发展的 最重要方面就是要控制水库磷含量的增加.

浮桥河水库投饵网箱养鱼一直维持很小的规模,没有扩大. 同时,水库集雨区内没有大的厂矿企业. 从 “水华”出现在水库中上游、并且在投饵网箱养鱼以上区域来看,引起浮桥河水库富营养化的主要原因是水 库集雨区径流带来的面源污染. 因此,要控制水库磷含量的增加, 就必须控制集雨区内农业生产和群众生 活所产生的各种污染物, 特别是控制磷随径流进人水库. 如农业生产要尽量减少化肥的施用量, 科学合理 施肥, 减少化肥, 特别是磷肥的流失. 在库区推广使用无磷洗涤用品. 同时, 要保护好库区植被. 另外, 水库 投饵网箱养鱼规模也不应该扩大.

\section{2 合理利用浮游植物初级生产力的渔业措施}

浮桥河水库 1997 年实际渔产量 (鲢鳙占 $95 \%$ 以上) 为 $396 \mathrm{t}$, 只有估算渔产潜力 $(772 \mathrm{t}$ ) 的 $51.3 \%, 1998$ 年 -2005 年水库年均渔产量 $384.1 \mathrm{t}$ (1998 年和 2005 年最低,均为 $252 \mathrm{t}, 2004$ 年最高 $477.5 \mathrm{t}$ ). 水库渔产量 与水库渔产潜力还有较大的差距, 水库浮游植物初级生产力还没有得到充分利用. 针对水库渔业生产现 状, 合理利用浮游植物初级生产力首先要加大捕捞强度, 目前鲢鳙起水规格较大, 在水库中生长时间偏长, 降低了初级生产力的利用效率. 应该降低捕捞网具网眼规格、加大捕捞强度来减小起水规格和提高渔产 量. 其次, 增加鲢鳙鱼放养量和调整鲢鳙放养比例. 增加鲢鳙鱼放养量可以加强鲢鳙对浮游生物的摄食强 度, 提高浮游植物初级生产力的利用率. 鲢处于食物链的第一级, 它转化浮游植物初级生产力的能量效率 比鳙要高,多放养鲢可以提高浮游植物初级生产力的利用效率. 以产量高、价格稍低的鲢去部分替代产量 
低、价格高的鳙在渔业经济效益上也不会有损失. 水库 1997 年 -2005 年年均鲢鳙鱼种放养量为 $7.87 \times 10^{4}$ $\mathrm{kg}$, 鲢鳙生长速度较快, 饵料供应较充足, 因此, 可以将水库每年鲢鳙放养量增加到 $10 \times 10^{4} \mathrm{~kg}$, 鲢鳙放养比 例由现在的 2.5:7.5 调整为 5:5, 以后视水质变化情况再进行调整. 第三, 合理减少食鱼性鱼类的捕捞量, 控制小型鱼类种群规模. 小型野杂鱼类通常以浮游动物为食, 与水库放养鱼类存在食物竞争, 它消耗了水 体饵料资源, 又没有实现渔业经济效益. 这对利用浮游植物初级生产力不利. 浮桥河水库小型鱼类丰度较 高, 其平均密度比湖泊高得多 ${ }^{[20]}$. 因此,要适当减少水库蒙古红鮊、尧呲红鮊、鳜和乌鳢等食鱼性鱼类的捕 捞量, 扩大这些鱼类的种群规模, 通过它们控制小型鱼类的种群规模, 可以减少初级生产力向小型野杂鱼转 移,提高水库浮游植物初级生产力的利用率.

上述措施同时还具有防止水库富营养化的加剧、防治局部“水华” 的作用. 鲢主要滤食浮游植物, 可以 直接控制浮游植物, 具有控制藻类 “水华” 作用 ${ }^{[19]}$. 鳙主要滤食浮游动物、小型野杂鱼类通常以浮游动物为 食, 这对发挥浮游动物控制浮游植物的作用不利. 减少鳙的放养量、控制小型鱼类的种群规模, 可以减轻对 浮游动物的摄食压力, 发挥浮游动物摄食小型藻类、控制水库局部“水华”的作用.

\section{4 参考文献}

[1] 王明学, 林可椒,邢鲁明等. 丹江口水库的水化学、初级生产力和鱼产力的研究. 水利渔业, 1990, (6): $26-31$.

[2] 何志辉,王喜庆. 碧流河水库的水化学、浮游生物和初级生产力. 大连水产学院学报, 1992,7(2、3):1 $-18$.

[3] 王卫民, 魏青山, 张世萍等. 宿鸭湖水库浮游植物初级生产力和鲢、鳙生产潜力的估算. 水利渔业, $1992,(2): 7-9$.

[4] 姜作发, 夏重志, 董崇智等. 蛤蟆通水库浮游植物初级生产力及能量转化效率的研究. 水产学杂志, $1995,8(2): 104-107$.

[5] 韩德举, 吴生桂,邹清等. 陆水水库的浮游生物及营养类型. 湖泊科学, 1996,8(4):351-358.

[6] 邬红娟,胡兴跃. 黑龙滩水库浮游生物及初级生产力. 水利渔业, 1998, (5):24-25.

[7] 姜作发, 夏重志, 董崇智等. 哈蟆通水库水位变化对浮游植物初级生产力及能量转化效率的影响. 中 国水产科学, 2001,8(4):23-26.

[8] 湖北省水库调查队. 黄冈地区 15 座水库的调查及渔业利用意见. 水库渔业, 1982,(4):10 - 20 .

[9] 吴晓辉,刘家寿, 朱爱民等. 浮桥河水库浮游植物的多样性及其演变. 长江流域资源与环境, 2003,12 (3) : $218-222$.

[10] 章宗涉,黄祥飞. 淡水浮游生物研究方法. 北京:科学出版社, 1993.

[11] 吴晓辉,朱爱民,杨大兴等. 浮桥河水库水质的理化特性. 水利渔业,2001,21(2):36-38.

[12] 刘健康主编. 东湖生态学研究 (一). 北京:科学出版社,1990:167 - 201.

[13] 王 骥,梁彦龄. 保安湖浮游植物密度、生物量和生产量的周年动态及渔产潜力的估算. 见: 梁彦龄, 刘 伙泉主编. 草型湖泊资源、环境与渔业生态学管理 (一). 北京:科学出版社, 1995:61-86.

[14] 王 骥,梁彦龄. 西凉湖浮游藻类现存量、生产量的季节变化及渔产潜力的估算. 见:梁彦龄,刘伙泉主 编. 草型湖泊资源、环境与渔业生态学管理 $(一)$. 北京:科学出版社, 1995:89-108.

[15] Winberg G G. Some interim results of Soviet IBP investigations on lakes. In: Productivity problems of freshwaters. Warszawa-Krakow, $1972: 263-381$.

[16] 何志辉. 中国湖泊和水库的营养分类. 大连水产学院学报, 1987,(1):1-10.

[17] 沈暳芬,章宗涉,龚循矩等. 微型生物监测新技术. 北京: 中国建筑工业出版社, 1990:120-139.

[18] Odum E P. Fundamentals of Ecology. W. B. Saunders Company, 1971:56.

[19] 刘建康, 谢 平. 揭开武汉东湖蓝藻水华消失之谜. 长江流域资源与环境, 1999,8(3):312-318.

[20] 刘家寿,陈文祥,黄永川等. 浮桥河水库的营养状况与水质调控措施. 长江流域资源与环境, 2001, 10 (4) :360 - 363 . 